ISSN 2227-7102

www.mdpi.com/journal/education

Article

\title{
Exploring the Impact of the Increased Tuition Fees on Academic Staffs' Experiences in Post-92 Universities: A Small-Scale Qualitative Study
}

\author{
Elizabeth A. Bates $^{1, *}$ and Linda K. Kaye ${ }^{2}$
}

1 Department of Psychology, University of Cumbria, Fusehill Street, Carlisle, Cumbria CA1 2HH, UK

2 Department of Psychology, Edge Hill University, St Helen's Road, Ormskirk, Lancashire L394QP, UK; E-Mail: Linda.Kaye@edgehill.ac.uk

* Author to whom correspondence should be addressed; E-Mail: Elizabeth.Bates@cumbria.ac.uk; Tel.: +44-1228-616-358.

External Editor: John Blewitt

Received: 9 September 2014; in revised form: 27 October 2014 / Accepted: 29 October 2014 / Published: 7 November 2014

\begin{abstract}
The introduction of the new tuition fee regime in the UK academic session 2012-2013 has resulted in concerns in the Higher Education (HE) community that students' expectations may become unmanageable. Previous research has explored the expectations and experiences of undergraduate psychology students; the current study extended this by considering whether the increased tuition fees have changed the experiences of academic staff in HE. To achieve this, five semi-structured interviews with psychology staff in two post-92 Higher Education Institutions (HEIs) were undertaken. Results suggested staff perceptions have undergone minimal change in their day-to-day experiences. However, perceptions of the wider HE issues, such as meeting targets and fulfilling requirements of the role, appear to be enhanced following the contextual changes of HE. Finally, the results reported here suggest generally good staff satisfaction, regardless of these changing times within the sector. Future research and the need for more widespread, large scale studies are discussed.
\end{abstract}


Keywords: expectations; tuition fees; academic employees; job demands; post-92 institutions; higher education

\section{Introduction}

\subsection{Background}

The recent increase in University tuition fees in the UK gave rise to concerns about the impact on student expectations. Tuition fees were first introduced in September 1998 with students contributing up to $£ 1000$ a year towards their University education. By January 2004 the cap was lifted further and institutions were able to charge "top up" fees of up to $£ 3000$ a year rising to $£ 3290$ a year by the year 2010. The Browne Review [1] recommended allowing Universities to charge up to $£ 9000$ a year which was implemented in England from September 2012.

With these large financial investments in Higher Education (HE), it was suggested that students' expectations of their university experiences were likely to change, resulting in greater dissatisfaction in instances of disparity between such expectations and the realities of their experiences [2]. It was suggested this may foster the perception of a "consumer culture" [3] in which students were expected to place greater demand on Higher Education Institutions (HEIs) to provide them with a service which met their financial investments.

In a response to these concerns, previous research has been dedicated to exploring these issues. Bates and Kaye [4] explored the expectations and experiences of first year undergraduate psychology students through a series of focus groups. These were obtained both before and after the introduction of the fee increase, as a means of providing the first systematic comparison of any pre-post fee rise changes in students' expectations of HE. Their findings revealed minimal support for the idea that increased tuition fees heightened students' expectations, with the exception that graduate employment aspirations were more apparent in the "post-fee rise" students.

The extent to which the fee rise issues may be relevant to the experiences of academic staff is yet unknown. Indeed, it is yet to be explored as to whether the potential changes in the demands of the working environment, as a result of the contextual shift, have been detrimental to the satisfaction of staff working in the sector. This forms the basis for the current study in which we aimed to examine such issues in light of the changing economic context.

\subsection{Change in the Context of Higher Education}

One key feature of the role of academic staff relates to the increased demand for producing research outputs, in addition to managing the teaching and administrative tasks of the role. This is reflected in commentary suggesting the "massification" of $\mathrm{HE} \mathrm{[5],} \mathrm{as} \mathrm{the} \mathrm{university} \mathrm{system} \mathrm{expanded} \mathrm{and}$ encompassed other educational institutions. A consequence of these changes includes the implementation of certain standards on academic staff in terms of qualifications, research and published outputs. Indeed, this is reflected in a review of 24 years of academic accounting where the proportion of staff with a $\mathrm{PhD}$ has risen from $9 \%$ to $39 \%$ [6]. The pressure on staff to publish has been framed in the 
context of their personal and professional development [7] but often has a negative impact on students and results in staff making strategic compromises with their time [8].

This pressure is exacerbated by research assessment regimes, suggesting increased pressure from both internal and external drivers [9]. Within HEIs the dominance of research activities has led to them becoming one of the most important criteria by which recognition, work and reward are based; again thought to be intensified by assessment regimes such as the Research Assessment Exercise (RAE; now known as the Research Excellence Framework, HEFCE [10]). This research culture has resulted in perceptions that academics either "publish or perish" within their role, which has been found to have detrimental effects, such as a loss of creativity, morale and actual research output [11]. Balancing teaching and research is one of the biggest challenges facing academic staff [12]; this balance of workloads and different role demands is seen as an increasing source of stress to academic staff.

\subsection{Balance of Work Roles}

Academia was once considered to be a low stress environment [13] but over the past 20 years, academic jobs have been found to be increasingly more stressful [14,15]. Academic staff workloads are largely framed by their performance in meeting the demands of both knowledge creation (research) and knowledge transmission (teaching), in addition to the service requirements of the sector [16]. Harman [17-19] investigated the changing nature of academia across a 20 year period between 1977 and 1997 and found academics in the later time period were reporting high satisfaction with their job roles but were critical of the levels of stress and associated salaries. Furthermore, there were increased workloads and pressure to engage in research and scholarly activity - the focus shifting from teaching to research. Although there is increasing pressure for academics to be responding to the needs of the students, they are also expected to be active in their generation of research outputs [20]. This is often as a direct result of the increasing financial self-reliant nature of UK HEIs [21], and the need to bring in more external funding. This conflict is often reflected in greater volume of tasks and unrealistic deadlines [22].

These increasing work demands present a concern in relation to staff well-being. Previous research has identified increased job demands to be associated with stress and psychological distress in academics [20]. Specific stressors relevant to academic-based roles include; time constraints, changing work environments, expanding student numbers, support and influence, professional identity, and work-home interference demands [16,23-26]. Such stressors have been found to have significant impact on physical and psychological health outcomes [21], suggesting the importance of monitoring the extent to which contextual changes in the sector are influential to the psychological well-being of academic staff. These concerns are not necessarily exclusive to the UK, given the growing body of literature detailing academic staff stress in a range of different countries including Canada [27]; Belgium [28] and South Africa [29] with much of the research currently having focused on the US [30] and Australia [31].

\subsection{Work-Life Balance}

Given the increasing stressors and job demands, the work-life balance is becoming more difficult for academics to maintain effectively. Work is often found to be invading non-work life in a psychological, 
as well as physical sense, and is manifested in preoccupation with work issues and difficulties with relaxing and sleeping [32]. It creates a negative "spill-over" from work to home [20] leaving staff increasingly less satisfied with their work-home balance [33]. The importance of a work-life balance to both the well-being of the employee and the organization has been widely acknowledged in the literature [34]. A work-life imbalance is a strong predictor of psychological distress and indeed having a better work-life balance is a good predictor of job satisfaction [35,36]. This is understandable as studies find that working evenings and weekends to cope with demands is commonplace among academic staff [20] with some of working in excess of the $48 \mathrm{~h}$ working week limit set by the EU time directive.

\subsection{Job Satisfaction}

Despite the issues with job demands and stressors there are still many academics reporting they are experiencing job satisfaction within their roles [26,27]. A commonly cited model of job satisfaction is Herzberg, Mauser and Snyderman's [37], which posited that job satisfaction is not one-dimensional but made up of separate and distinct work related variables. Pearson and Seiler [38] found academics were generally satisfied with their work environment but dissatisfaction came from specific factors such as management style, development opportunities, colleagues, being appreciated, autonomy, physical environment, work-life balance, and wage [35,39]. An exploration of the day-to-day experiences of academic staff is therefore an important consideration, given the implications on psychological and physical well-being [39]; this is especially true in light of the changing HE climate.

The current small-scale qualitative study aimed to explore these issues by undertaking a series of interviews with academic staff within two UK HEIs, to assess the extent to which the increase in tuition fees as a key economical change, may have affected the experiences of academic staff working in HE in these two UK post-92 institutions. This is the first study of its kind to explore these issues since the introduction of the higher tuition fees in 2012.

Specifically, a number of research questions were developed:

(1) To what extent has the increase in tuition fees changed academic staffs' day-to-day experiences of teaching and student support?

(2) How do academic staff perceive that these wider contextual changes within HE to have affected their experiences?

(3) To what extent has the increase in tuition fees affected academic staffs' job satisfaction?

\section{Materials and Methods}

\subsection{Participants and Procedure}

Participants were recruited through targeted sampling of Psychology academics through email advertising at two UK HEIs. In total, five semi-structured interviews were conducted, each lasting approximately one hour. This included two males and three females and a range of experience in post including a principal lecturer, an associate tutor, and lecturers/senior lecturers, who were sampled from the two UK HEIs. Interviews took place between May and September 2013 towards the end of the first academic year with the fee rise in place. 


\subsection{Institutions}

Participants were recruited from the same two HEIs used in the original data analysis in Bates and Kaye [4]. These are two modern campus-based universities, which offer traditional Psychology degree courses, and have similar tuition fee requirements ( $£ 9000$ and $£ 8400$ per annum). Both are "post-92" era institutions. Post-92 era universities refer to any former poly-technic, central institution or Higher Education college given University status by the UK Government in 1992 through the Further and Higher Education Act (1992). Both HEIs attract a mixture of local "stay-at-home" students and those coming from further away; these were chosen as they do not represent the traditional Russell Group which generally are leading research Universities and receive more funding through research and scholarly activity.

\subsection{Agenda}

The interview schedule was developed to access issues raised by the previous literature and those raised in the student focus groups. There were a number of issues explored:

(1) Perceptions of students' Higher Education expectations

(2) Perceptions of institutional expectations

(3) Experiences of work demands and job roles

All interviews were recorded using a digital recorder for the purpose of full transcription. Thematic analysis was chosen for analysis as it is a useful way of identifying, analyzing and reporting themes in qualitative data [40]. It can also provide a rich, detailed account of data. The analysis process was conducted in line with Braun and Clarke's [40] suggested phases for thematic analysis.

\section{Results and Discussion}

The following section discusses the findings and highlights the experiences of academic staff in their job role. This is presented in three main sub sections: "Students' experiences", "Contextual Change within Higher Education" and "Satisfaction".

\subsection{Students’ Experiences}

\subsubsection{Approach to studying}

Staff had noticed differences in students' approaches to studying; this encompassed their independence in learning, motivations and overall engagement. Staff found students to be more motivated, and in some cases, more independent than students in previous cohorts:

“...it's always traditionally... well our A-Level teachers told us everything why won't you tell me exactly what's on that question paper...but this year I didn't find the first years like that..." (Participant 1)

This is in line with findings from recent studies suggesting the increased tuition fee rise has not affected student expectations but rather their motivations to studying [2]. Students appeared more 
motivated to work to succeed due to making such large financial investments and to get the most from their experiences:

“...the opposite has happened to what I expected...I thought they would be really demanding and obnoxious because they were telling us they were paying us, my salary whatever and I've not had any comments like that...it's been very much erm...they're here to learn and they've actually largely engaged completely with that..." (Participant 1)

This was stated to be in marked contrast to previous year groups:

"Yeah erm...I have noticed a difference actually, a marked difference, in the first years. Erm, in that they seem to have been more committed..." (Participant 2)

The first years, now, are already thinking about dissertations...that tells you something. Whereas I sometimes got the impression with the second year group that... it was more, almost like well I'm just here because I can be (Participant 3)

In addition, academic staff perceived this was also the case for autonomy in learning:

"Yeah, I think they're more motivated...more inclined to seek help...than previously... they're taking more responsibility for their own learning because it's costing so much." (Participant 2)

This suggests that students are engaging more and taking ownership of their learning experiences. Some staff referred specifically to the fee rise suggesting that students are taking more personal responsibility because it is their own money (or debt) paying for their degree rather than it being subsidised by the Government:

“...they see it as their money being spent...there's more personal responsibility on what they're spending now." (Participant 3)

This was also demonstrated in staff perceiving that students seemed to hold greater appreciation for initiatives such as study skills and extra-curricular activities, which again demonstrates engagement in their leaning:

"...maybe it has got something to do with the money I don't know but...a lot of them do still to be more engaged and interested in what's going on in the university and in joining extracurricular things" (Participant 4)

These perceptions appear to suggest an underlying role of the increased tuition fees in the approach of students. This appears to be reflected in indicators such as motivation and autonomy, which staff perceive as being greater in the first cohort of higher fee payers, compared to their lower-fee paying counterparts. These findings are in contrast with previous commentaries which suggested students would be more demanding as "consumers" [2]. This appears to support previous findings that the increased tuition fees has had little detriment on students' expectations of their HE experiences [4], rather the increased fees is increasing personal responsibility for learning, expecting more of themselves rather than of academic staff. It suggests a change in the way students are approaching their studying and a change in their motivations [41], whilst on the surface this would not necessarily have a negative impact on staff it depends on the way in which students believe staff should facilitate this. 


\subsubsection{Employability Expectations}

One area in which academic staff perceived a difference in student expectations was in the area of employability; not just what students expected from university, but in their general approach to career and personal development. Participants' narratives also covered the role of the wider employability agenda and how this impacted on staff in terms of their role and their workloads:

“There's so much emphasis on employability... I think if you ask any...fourteen year old at secondary school, they are talking about employability skills and they, they're familiar with those kind of key buzzwords er, and I think our students definitely expect that and they expect us to be fully aware of that." (Participant 3)

As with approaches to learning, staff perceived students as taking more responsibility in enhancing their personal and professional development. Within this, there was the perception that students were becoming more strategic in selecting courses which provided them with greater graduate employment;

"Erm, but I think we've moved beyond that idea of liberal education, doing it because you're interested in it. I think for quite some time now, it's been erm, a sort of career led thing hasn't it?" (Participant 2)

This suggests that students are now not necessarily choosing degree subjects based on interest and are instead thinking about their career path as a focus. This is in line with findings highlighting the career-related motivations of students, particularly those paying higher fees [41], and their expectations regarding graduate employment [4].

Participant 2 further suggested that the employability agenda within the sector had led to a shift in the way subjects are taught:

$\mathrm{R}:$ “...Do you perceive it to be very different in the last nine years, then?

P2: Yeah, quite a lot different actually, you know, going back to that idea of liberal education erm, and teaching... a subject, rather than developing people professionally and to go on and do a career. Yeah, it's, the focus has shifted considerably." (Participant 2)

This suggests a shift in the traditional scholarly relationship, with emphasis now on providing greater employability provisions to enhance employability skills. This supports the previous findings of Thompson, Clark, Walker and Whyatt [42] who found students to be largely active in engaging themselves in extracurricular activities, and showing acknowledgement of the implications on their employability. This presents a wider issue for HEIs in their approach to encouraging students to involve themselves in such activities. The significance of student demands for employability are likely to create an additional role to which academic staff are to respond. Beyond the teaching, research and administrative roles there is now the addition of this aspect that falls into career advice and personal development. Research has shown that increased job demands has increased stress in academic staff [20] which in turn have significant impacts on both physical and psychological health [21]. Should research demonstrate these demands are ever increasing in the new HE climate then recommendations for building these activities into workload discussions. 


\subsubsection{Expectation of Staff Accessibility}

Staff perceived an increase in students' expectations surrounding level of communication and accessibility:

"I think they had fairly high expectations...the first years seem to...want more...they seem to expect us to be much more accessible then we are...but I have noticed a difference, yeah it's perhaps more of an entitlement." (Participant 2)

This was reinforced by Participant 3 who further added some insight into the role of personal responsibility on the part of the student:

"I think they certainly expect certain things in terms of communication, I think we're almost

like a bank call center in some regards. They, they expect...you know I've paid for this service, and I want to make the most of it' from that point of view." (Participant 3)

In line with Jones' [2] commentary, the increased fees may result in higher student expectations in terms of greater communication with tutors, and may stipulate an "immediate response...irrespective of the time or day" [2] (p. 45). This is potentially detrimental to staff workloads and work-life balance. Staff increasingly feel pressure from HEIs to respond to the needs of their students and to demonstrate they are responding to student feedback [2]. Participant 4 commented that this affects the amount of time staff are spending on campus:

"...I do think the expectations are high on staff in terms of that...we've got to make sure we deliver the goods because they're paying so much money...I do notice that visibly staff are around a lot more than they used to..." (Participant 4)

Increased student expectations can lead to increased pressure on staff to respond and meet the demands of the students, this likely means working outside contracted hours leading to a negative "spill-over" from work to home [20] and affecting the work-home balance [34]. Further studies have indicated the potential for this imbalance to lead to psychological distress [27] highlighting the importance of these implications.

With the exception of expectations of communication, it seems that staff perceptions of higher-fee payers is largely positive, in terms of their general approach to studying and their wider personal and professional development. Considering the implications of these findings, suggestions include clear communication to students on staff accessibility (e.g., office hours) as a key requirement. Additionally, this may point to alternative communication channels, such as social media as a means of ensuring students are receiving adequate communication with staff [43]. These strategies may only be effective if there is consistency in the usage by both parties [44].

\subsection{Contextual Change within HE}

\subsubsection{Students as Consumers}

One of the biggest concerns that arose with the increase in tuition fees was the likelihood that HEIs and staff would be expected to treat students as customers moving away from the traditional scholarly 
relationship [2,45]. This concern has come to fruition in some respects and was evident within the data:

"I think there's a much higher expectation to treat students as customers and clients... everybody I work with has always treated as students with respect and...as...not customers but as colleagues as partners in learning so I find it quite frustrating...” (Participant 1)

Here participants further discussed the idea of a shift in what was expected of them generally, referring to both students and the wider HE community:

"I think also that erm you know the goals posts have been moved and it's up to us to step up to the mark" (Participant 4)

This notion of the student as a customer is emphasized by sector wide initiative such as the National Student Survey (NSS; a nationwide survey giving final year student the opportunity to rate their university experience) and the publications of Key Information Sets (KIS; data that allows students to compare HEIs on a number of important aspects e.g., how many hours contact time) which allows students to compare HEIs in an equivalent way to consumers purchasing any product of significance. Students as customers is further evidenced in data that details the number of student complains rising each year [46]. In the current data, there is an emphasis on the cyclical nature of this relationship; the pressure on staff affects their attitudes towards the students which then alters the students' attitudes towards the staff:

"I think the change in expectations is coming from staff, I think we have an expectation...we go overboard, we ask them constantly are you happy, are you ok... I think it's the nature of the students to go I need to find a problem, they're asking me to find a problem; therefore I'm going to find a problem..." (Participant 5)

This suggests the issues might relate to expectations about students rather than those derived from students themselves indicating pressure from the wider HE community. Regardless of where the pressure originates, it still creates a concern for issues such as the work-life balance and the impact of additional stress of physical and psychological health. The "negative spill-over" has been associated with health issues including difficulties sleeping [32]. A work-life imbalance has ramifications for academic staff $[35,36]$ but also for the employer and organization [34] suggesting it would be beneficial for all involved if this balance was maintained.

\subsubsection{Data and Targets as Drivers}

Part of the pressure academic staff experienced from institutions appeared to be derived from the drivers of institutional reputation such as the NSS and KIS data. Participant narratives appeared to reflect this:

"R: Do you feel pressure from the university in terms of making sure that they're [the students are] satisfied?

P1: Oh yeah, God I've written five reports on feedback on NSS this year, five! Five!"

These external drivers place emphasis on staff to not only achieve satisfaction but ensure that it is being measured appropriately. These data drivers appeared to further feed into the attitude of treating 
students as customers. It was also found to lead to a level of competition between the different HEIs but some staff believe the anticipation and worry of the extra pressure these could bring lead to a bit of an anti-climax:

"I think there was a huge preparation and drive for us to have this customer orientation...and I think we've wasted a lot of time worrying about stuff we already do well...like the KIS data..." (Participant 1)

External targets and pressures therefore appear to feed down to academic staff in ensuring they are adequately providing a satisfactory student experience, resulting in increased worry and potential stress for those in "front-line" roles. This is somewhat reflective of the notion of "performativity" which represents a more general cultural shift in the way in which society focuses on judgment and measurement, to ensure regulation [47], which has resulted in personal beliefs and commitments being thwarted to permit "an existence of calculation" [47] (p. 215). The current findings are reflective of those of previous studies indicating the role of the performative culture on educational practice [48], and how the tensions between different aspects of the academic role may impact on the extent to which academics are able to respond effectively to students. The current findings seem to suggest "students as consumers", and the implications for staff, are derived through institutions and "national panic" rather than the students themselves. However, there are still concerns on the pressure this creates for staff.

\subsubsection{Institutional Demands}

The institutional level demands were discussed in greater depth by participants. Specific issues related to emphasis on success, the opposing pressure of HEIs and students, and the general increase in workload. Participant 1 discusses how the pressure to increase and ensure the satisfaction of the students actually results in less engagement with them:

"...our job is to see them succeed and as long as they know that is what our motivation is throughout, then the students will be fine, unfortunately...we need to tick more boxes and spend more time proving that and I think therein lies the error" (Participant 1)

The frustration here is evident with the conflict between personal motivation and institutional pressure. Feeling stretched to cover all aspects of the role and the attribution of "failures" in the role appeared to be a change within the HE context as reflected by Participant 5's narrative:

“...the University pulls us in one direction, the students pull us in another and then we have our own personal goals that pull us in another...that emphasis of doing more with less..." (Participant 5)

The changing nature of HE therefore appears to have resulted in there being conflicting pressures on staff. Staff are encouraged to think of students as consumers and ensure they are satisfied, whilst simultaneously being pressured to publish research output ("publish or perish"):

"R: What do you think about the university's expectations of you...what do you feel like that has changed?

P: Oh yeah, yeah erm my remit will be to become more research active...but also the other responsibilities erm...you know that things like...equality and diversity...” (Participant 4) 
Academic staff perceive that they are seen as the "agents" of success both through students' satisfaction (e.g., NSS) and research and scholarly activity (e.g., quality publications, Research Excellence Framework). Increased workloads to meet these demands appear to create pressure rather than motivation towards these institutional goals - specifically in relation to research. This links back again to research pressures (discussed below) and the increase in variety of job roles academic staff are expected to fill. This threatens job satisfaction [39] and the work-life balance but increasing pressure for staff to work beyond their contracted hours $[35,36]$.

\subsubsection{Research Pressures}

A strong theme emerged within all interviews related to the pressure to be research active and its implications for managing job roles. The nature of the HE environment has evolved over recent years with one of the main changes being the emphasis placed on research. HEFCE [10] report that there has been a dominance of research-related activities in criteria for which staff are now recognized and rewarded with teaching becoming the least extrinsically-rewarded activity. This notion was prominent in discussions with staff:

"I do know now, new staff erm coming in erm I wouldn't say under pressure but I think erm maybe it is you know, that they have to be more research active, yeah..." (Participant 4)

This finding is supported by studies which examined the change in research culture; Billot [9] found $33 \%$ of academics prioritized research to a greater extent and had linked research assessment regimes with growing frustration in the role. Discussions from the current sample highlight the change in their role that accompanied this increased pressure to research:

"The role within teaching that's changed and the role within our own teaching role has changed to one of researcher/lecturer from a lecturer/researchers..." (Participant 5)

This indicates a shift in priorities but also in identity within their job role, whereas they previously felt they were primarily a teacher who did research they now feel they are more of a researcher who does teaching. Other staff members were frustrated by this conflict between their roles:

“...but I really do feel sometimes that erm...you know that you are sort of pulled in both directions...sometimes you see things you know, not being done maybe because there's more emphasis on output, the research..." (Participant 4)

Another participant alluded to the fact this was propelled by the external drivers of both the research and teaching/students:

"NSS, we are constantly told about NSS, and then in the same breath they say erm the REF has to be done...well what do you want me to do first? I can't do it all..." (Participant 5)

Increasing pressures from different aspects of the job roles leads to a greater workload for staff with some perceiving that those to lose out are the students:

“...it's getting students to...that are traditionally 58, 2.2 students into the 62, 2.1 students they're now not being pushed and not being seen simply because you don't...right I've got 
an hour here do I see the student and email them if they're ok or do I do some research, it's do the research unfortunately..." (Participant 5)

Research pressure may have negative implications surrounding workload and also impact on effective support for students. These findings should be interpreted with caution in generalizing beyond post-92 HEIs, as the extent to which academic staff are experiencing this shift may be relatively new compared to within Russell Group institutions. The research pressures for academic staff may be more "normalized" within more heavily established research institutes. As a response to the concerns regarding research pressures, it would seem appropriate for HEIs, particularly of the post-92 era, to consider the criteria for fostering a healthy and productive research environment in times where output is deemed so valuable. Previous research has demonstrated the effectiveness of several methods for increasing productivity including writing retreats [49] and fostering good social interactions between researchers [50]. Trying to improve the research culture could lead to increased productivity and decreased frustration with the activity.

To accommodate this changing HE context, greater transparency in the system is key [47] to help academic staff understand the institutional priorities and to aid their work-load management. This may be currently problematic for some post-92 institutions which may still be in "identity crisis" and in flux as to their priorities. Post-92 institutions, traditionally branded as "teaching-focused" institutions, may struggle to articulate to their staff where the priority lies, resulting in tensions in managing and prioritizing work-load.

Research has discussed ways to address issues with workload in academic roles, one such way being flexible work arrangements. Flexible work arrangements (having flexibility in choosing where and when work is to be completed) has been found be associated with moderate job satisfaction. Furthermore, a consideration of movement towards a set workload model, in which there are specific hours allocated for activities such as teaching, administration and research. These have previously been used in the UK [51] and may alleviate the likelihood of academic staff experiencing lower well-being, higher stress and potential absence from work.

\subsubsection{Retention as Driver}

A further theme identified was retention as a driver and the associated pressures to facilitate this process. The rise in the tuition fees resulted in a national reduction in student numbers which has placed a financial pressure on HEIs to ensure the retention is managed effectively. As a consequence of this, it was revealed that participants felt a stronger focus was placed on the "students at risk" and taken away from the more academically-talented ones:

"...we focus often much more on the less able students, than the gifted and talented students, and I think there's an institutional expectation of the consequence of early retention issues." (Participant 3)

Widening participation schemes and the notion of HE becoming more accessible has increased the diversity within the student body [52]. This brings with it a responsibility to ensure all students are supported in the best way to ensure they can succeed. However, the time-consuming nature of administration relating to retention was highlighted in relation to managing work-loads: 
"...the emphasis was on erm trying to keep students, keep them retain them, do everything you can to retain them, but now it's like well do all of that plus do your research" (Participant 5)

Taken together, the narratives reveal evidence of increasing pressure on staff from various sources, including management, wider retention and data drivers, and the strain of meeting perceived students' expectations. These pressures have been found to be experienced rather negatively by academic staff, particularly in managing workloads and work-home balance [39]. As discussed above, it is likely these specific issues are restricted to post-92 institutions rather than the more established Russell Group universities. It is important that future research explores these issues in a wider range of UK universities to allow a more representative picture to emerge of the current HE climate across the country.

\subsection{Satisfaction}

\section{Team Support}

A noteworthy finding in all participants' narratives related to the notion of team support in buffering the effects of a stressful work environment. Indeed, this seemed to be as a source of social support when workload pressures were at their peak:

"I don't think I've ever worked anywhere and felt so much part of a team... I think that changes the whole dimension because even when your well-being is being affected you just email one of the team and say please can you help...there's a real collegiate feel." (Participant 1)

This collegiate reciprocity seemed to be a significant contributor to job role satisfaction:

R: "Erm, do you think that there's any other factors then that are contributing to your experience in your job role, so how much you enjoy it or...?

P2: The team that I work with...” (Participant 2)

This support seemed to manifest itself through loyalty to their team members, enabling them to work functionally with mutual trust. It further seemed that this sense of team support was reflected by effective communication:

"I think that it is a hard job...it's you know it's not an easy job it's a hard job but I think we're...fortunate that we've got a nice team erm and we communicate well with each other" (Participant 4)

Within our current sample academic staff seemed to be satisfied with their jobs, their roles and support from their colleagues. Despite the extensive pressures and the changing context of HE, staff spoke positively about their jobs, which fits with previous research highlighting that despite job demands and stressors, staff are still experiencing job satisfaction within their roles [27]. It is possible that as the current study used only two HEIs that this is not the same across the sector but it provides some insight into job satisfaction in post-92 institutions. Herzberg et al.'s [37] model of job satisfaction suggests job satisfaction is not in fact one-dimensional but made up of separate and distinct work-related variables, which is supported by other research $[35,38,39]$. The results of the current 
study have highlighted there are many factors contributing to the satisfaction of the academic staff in our sample, but the strongest theme was overwhelmingly being supported by colleagues and having the support of them team.

\subsection{Limitations of the Study}

The findings of the current study reveal some insight into the experiences of academic staff in these two institutions in the context of the HE fee rise, something that is previously unexplored in the literature. It is important to note that the conclusions drawn are limited in two ways. The first involves the methodology and specifically the sample size. Using a qualitative research design requires smaller sample sizes to be able to fully analyze the data but as a consequence it means large generalizations are not possible here. Secondly, it is hoped the results will be of interest to other post-92 universities in the UK that may be undergoing similar changes and experiences but they are unlikely to be of significant interest to Russell Group and larger research-focused universities that are facing different pressures in the current climate. That said, it is hoped these findings may form the basis of future research that explores these issues in a larger more varied sample. Future directions for research in this area should include wider scale quantitative based studies that allow exploration of these issues in not only a greater number of post-92 institutions but also within the more research focused universities. This would allow the exploration of whether the tuition fee rise has impacted these institutions in a similar way, if at all.

\section{Conclusions}

The aim of the current study was to explore the experience of staff in light of the introduction of higher UK tuition fees. Whilst recognizing the limitations detailed above, this study is the first of its kind to explore the experience of academic staff in the UK since the introduction of the higher tuition fees in 2012. Although we do not contend that the higher fees have a direct impact on staff experiences, we do suggest indirect effects through processes such as heightened perceptions of student expectations and changes in staff management priorities. It appears that the staff in our current sample do not perceive students to be greatly different in their expectations compared to previous lower-paying cohorts (certainly not in negative terms); however, HEIs and management expectations were seen to be different. Management was perceived to exert pressure on staff to treat students as consumers; to ensure staff made themselves more available and accessible. Through this, it appears that staff perceived increased pressure in their job roles, which appear to be driven by institutional demands but also by external drivers to engage in more research and scholarly activity - the latter reflecting the so called "publish or perish" notion.

Regarding these research issues and pressures, the changing climate and context of the sector is not something which can be addressed by individual HEIs, so recommendations here are focused more around how these HEIs can make a research agenda more manageable for their staff. First and foremost, it is felt that staff must be allocated adequate time to accomplish all elements of their job role. The push to engage in research activity should be something that is built-in to workloads and workload models. Themes surrounding job satisfaction included the support of colleagues; developing a research community that has a similar team spirit would help staff engage more with this. Research assessment 
exercises are likely to increase pressure rather than motivation. This suggests utility in encouraging research activity, and rewarding through the process rather than just the output. This is a challenge in itself when HEIs and their success are measured purely by the outputs and engagement.

Regardless of these discussed pressures, the staff interviewed in our research were generally satisfied with their role and did not report huge dissatisfaction in any area. Although this finding may only be relevant for the target institutions, there are some implications of the discussed pressures which hold greater relevance to the wider sector. Should future research using more large scale studies reveal similar findings, it would call for recommendations focusing on ways in which HEIs and staff should embrace the changes in the sector whilst calling for greater insight into strategies for ensuring work-life balance and maintaining job satisfaction.

\section{Author Contributions}

The work represented here reflects joint contributions from both authors in the formulation of the research, the data collection, analysis and written report.

\section{Conflicts of Interest}

The authors declare no conflict of interest.

\section{References}

1. Browne, J. Securing a Sustainable Future for Higher Education: An Independent Review of Higher Education Funding and Student Finance, 2010. Available online: https://www.gov.uk/government/uploads/system/uploads/attachment_data/file/31999/10-1208securing-sustainable-higher-education-browne-report.pdf (accessed on 22 July 2013).

2. Jones, G. Managing student expectations: The impact of top-up tuition fees. Perspectives 2010, $14,44-48$.

3. Woodall, T.; Hiller, A.; Resnick, S. Making sense of higher education: Students as consumers and the value of the university experience. Stud. High. Educ. 2014, 39, 48-67.

4. Bates, E.A.; Kaye, L.K. "I'd be expecting caviar in lectures": The impact of the new fee regime on undergraduate students' expectations of Higher Education. High. Educ. 2014, 67, 655-673.

5. Matthews, M.R. Publish or perish: Is this really a viable set of options? Account. Educ. 2007, 16, 225-240.

6. Brown, R.; Jones, M.; Steele, T. Still flickering at the margins of existence? Publishing patterns and themes in accounting and finance research over the last two decades. Br. Account. Rev. 2007, 39, 125-151.

7. Keen, A. Writing for publication: Pressures, barriers and support strategies. Nurse Educ. Today 2007, 27, 382-388.

8. Skelton, A. Value conflicts in higher education teaching. Teach. High. Educ. 2012, 17, 257-268.

9. Billot, J. The changing research context: Implications for leadership. J. High. Educ. Policy Manag. 2011, 33, 37-46. 
10. HEFCE. Appointment, retention and promotion of academic staff in higher education institutions: A report to the HEFCE by the Scottish Council for Research in Education; University of Glasgow and Nottingham Trent University: London, UK, 2003.

11. Wilson, A.; Sharrad, S.; Rasmussen, P.; Kernick, J. Publish or perish: Ensuring longevity in nurse education: Evaluation of a strategy to engage academics, students and clinicians in publication activity. J. Prof. Nurs. 2013, 29, 210-216.

12. Sarah Marten. The Challenges Facing Academic Staff in UK Universities, 2009. Available online: http://www.jobs.ac.uk/careers-advice/working-in-higher-education/1350/the-challenges-facingacademic-staff-in-uk-universities (accessed on 1 September 2013)

13. Willie, R.; Stecklein, J.E. A three decade comparison of college faculty characteristics, satisfactions, activities, and attitudes. Res. High. Educ. 1982, 16, 81-93.

14. Kinman, G. Pressure points: A review of stressors and strains in UK academics. Educ. Psychol. 2001, 21, 473-492.

15. Gillespie, N.A.; Walsh, M.; Winefield, A.H.; Dua, J.; Stough, C. Occupational stress in universities: Staff perceptions of the causes, consequences and moderators of stress. Work Stress 2001, 15, 53-72.

16. Houston, D.; Meyer, L.H.; Paewai, S. Academic staff workloads and job satisfaction: Expectations and values in academe. J. High. Educ. Policy Manag. 2006, 28, 17-30.

17. Harman, G. Academics and institutional differentiation in Australian higher education. High. Educ. Policy 2001, 14, 325-342.

18. Harman, G. Academic leaders or corporate managers: Deans and heads in Australian higher education, 1977 to 1997. High. Educ. Manag. Policy 2002, 14, 53-70.

19. Harman, G. Australian academics and prospective academics: Adjustment to a more commercial environment. High. Educ. Manag. Policy 2003, 15, 105-122.

20. Kinman, G.; Court, S. Psychosocial hazards in UK Universities: Adopting a Risk Assessment Approach. High Educ Q 2010, 64, 413-428

21. Kinman, G.; Jones, F. Work-life balance and wellbeing in academics. In Key Papers of the European Academy of Occupational Health Psychology; McIntyre, S., Houdmont, J., Eds.; ISMAI Publications: London, UK, 2006.

22. Necşoi, D.V.; Porumbu, D. Occupational Stress in University: Perceived causes and coping strategies. In Proceedings of the International Conference of Scientific Paper (AFASES), Brasov, Romania, 26-28 May 2001.

23. Gmelch, W.H.; Wilke, P.K.; Lorrich, N.P. Dimensions of stress among University faculty: Factor analytic results from national study. Res. High. Educ. 1986, 24, 266-286.

24. Kinman, G. Work stressors, health and sense of coherence in UK academic employees. Educ. Psychol. 2008, 28, 823-835.

25. Kinman, G.; Jones, F. Running up the down escalator: Stressors and strains in UK academics. Q. High. Educ. 2003, 9, 22-37.

26. Lacy, F.J.; Sheehan, B.A. Job satisfaction among academic staff: An international perspective. High. Educ. 1997, 34, 305-322.

27. Catano, V.; Francis, L.; Haines, T.; Kirpalani, H.; Shannon, H.; Stringer, B.; Lozanzki, L. Occupational stress in Canadian Universities: A national survey. Int. J. Stress Manag. 2010, 17, 232-258. 
28. Decramer, A.; Smolders, C.; Vanderstraeten, A.; Christiaens, J. The impact of institutional pressures on employee performance management systems in Higher Education in low countries. Br. $J$. Manag. 2012, 23, 88-103.

29. Bezuidenhout, A.; Cilliers, F.V.N. Burnout, work engagement and sense of coherence in female academics in higher-education institutions in South Africa. J. Ind. Psychol. 2010, 6, 1-10.

30. Ablanedo-Rosas, J.H.; Blevins, R.C.; Gao, H.; Teng, W.Y.; White, J. The impact of occupational stress on academic and administrative staff, and on students: An empirical case analysis. J. High. Educ. Policy Manag. 2011, 33, 553-564.

31. Boyd, C.M.; Bakker, A.B.; Pgnata, S.; Winefield, A.H.; Gillespie, N.; Stough, C. A longitudinal test of the job demands-resources model among Australian University Academics. Appl. Psychol. 2011, 60, 112-140.

32. Netemeyer, R.G.; Boles, J.S.; McMurrian, R. Development and validation of work-family conflict and family-work conflict scales. J. Appl. Psychol. 1996, 81, 400-410.

33. Sharafizad, F.; Paull, M.; Omari, M. Flexible work arrangements: Accessibility in a University Environment. Aust. Univ. Rev. 2011, 53, 43-49.

34. Lewis. S.; Cooper. C. Work-Life Integration: Case Studies of Organisational Change; Wiley: England, UK, 2001.

35. Chung, K.C.; Song, J.W.; Kim, H.M.; Wooliscroft, J.O.; Quint, E.H.; Lukacs, N.W.; Gyetko, M.R. An analysis of the levels of job satisfaction and life satisfaction of the academic staff differ? Med. Educ. 2010, 44, 985-995.

36. Lambert, E.G.; Hogan, N.L.; Barton, S.M. The impact of work-family conflict on correctional staff job satisfaction: An exploratory study. Am. J. Crim. Justice 2002, 27, 35-52.

37. Herzberg, F.; Mausner, B.; Snyderman, B.B. The Motivation to Work; John Wiley and Sons: New York, NY, USA, 1959.

38. Pearson, D.A.; Seiler, R.E. Environmental satisfiers in academe. High. Educ. 1993, 12, 35-47.

39. Filiz, Z. An analysis of the levels of job satisfaction and life satisfaction of the academic staff. Soc. Indic. Res. 2014, 116, 793-808.

40. Braun, V.; Clarke, V. Using thematic analysis in psychology. Qual. Res. Psychol. 2006, 3, 77-101.

41. Kaye, L.K.; Bates, E.A. The impact of the new fee regime on psychology students' reasons for attending university. Psychol. Learn. Teach. J. 2014, under review.

42. Thompson, L.; Clark, G.; Walker, M.; Whyatt, D. "It's just like an extra string to your bow": Exploring Higher Education students' perceptions and experiences of extra-curricular activity and employability. Act. Learn. High. Educ. 2013, 14, 135-147.

43. Judd, T. Facebook versus email. Br. J. Educ. Technol. 2010, 41, 101-103.

44. Knight, C.; Kaye, L.K. To Tweet or not to Tweet? A comparison of academics' and students' usage of Twitter in academic contexts. Innov. Educ. Teach. Int. 2014, doi:10.1080/14703297.2014.928229.

45. Jones, G. "I wish to register a complaint": The growing complaints culture in Higher Education. Perspectives 2006, 10, 69-73.

46. Office of the Independent Adjudicator. Annual Report 2012. Available online: http://oiahe.org.uk/media/88650/oia-annual-report-2012.pdf (accessed on 22 July 2013).

47. Ball, S.J. The teacher's soul and the terrors of performativity. J. Educ. Policy 2003, 18, 215-228. 
48. Biesta, G. Good education in an age of measurement: On the need to reconnect with the question of purpose in education. Educ. Assess. Eval. Account. 2009, 21, 33-46.

49. Singh, R.J. Promoting writing for research: The "writing retreat" model. S. African J. High. Educ. 2012, 26, 66-76.

50. Salaran, M. Research productivity and social capital in Australian Higher Education. High. Educ. Q. 2010, 64, 33-48.

51. Perks, S. Academic Workload: A model Approach. 2013. Available online: http:/www.theguardian.com/higher-education-network/blog/2013/apr/15/academic-workloadmodelling-management (accessed on 1 September 2013).

52. Trahar, S. Changing landscapes, shifting identities in higher Education: Narratives of academics in the UK. Res. Educ. 2011, 86, 46-60.

(C) 2014 by the authors; licensee MDPI, Basel, Switzerland. This article is an open access article distributed under the terms and conditions of the Creative Commons Attribution license (http://creativecommons.org/licenses/by/4.0/). 